\title{
Melatonin and sciatic nerve injury repair: a current perspective
}

This article was published in the following Dove Press journal: Journal of Neurorestoratology

\author{
Berrin Zuhal Altunkaynak' \\ Burcu Delibaș² \\ Gamze Altun² \\ Ömür Gülsüm Deniz ${ }^{2}$ \\ 'Department of Histology and \\ Embryology, Medical Faculty, \\ Okan University, Istanbul; Turkey; \\ 2Department of Histology and \\ Embryology, Medical Faculty, Ondokuz \\ Mayıs University, Samsun, Turkey
}

Correspondence: Berrin Zuhal Altunkaynak

Department of Histology and Embryology, Medical Faculty, Okan University Okan University Tuzla Campus, 34959 Tuzla/lstanbul, Turkey Tel +90216677 1630 ext 3870

Email berrinzuhal@gmail.com

\begin{abstract}
Peripheral nerve injury is an important clinical problem that can exert hazardous effects on the health of patients. For this reason, there are more studies conducted on the regeneration of the peripheral nerves via the usage of the nerves belonging to various animals with different types of lesions, ages, and by using different methods of assessment with regular follow-up. Contrary to data obtained through experimentation and clinical observation, no ideal way of treatment was found to increase the regeneration of the peripheral nerves. Finally, the effects of melatonin in the protection of peripheral nerves against trauma, especially the protection of sciatic nerve from pathological conditions, have come into attention in a wide group of scientists as there are beneficial effects of melatonin after surgery. While numerous studies indicate the melatonin's protective effects on the pathologies of nerves, there are also studies reporting its toxic effects on peripheral nerves. Melatonin is a widespread and crucial signaling molecule due to its features of free radical scavenging and anti-oxidation at both pharmacological and physiological conditions in vivo. In this context, although there are numerous studies elaborating the effects of melatonin in various tissues, its effects on peripheral nerves was documented in only a limited number of studies. The aim of this article was to perform a review of the knowledge in the literature on the subject of mostly beneficial or hazardous effects of melatonin on the repair of the damaged peripheral nerves.
\end{abstract}

Keywords: peripheral nerve injury, melatonin, regeneration, light and electron microscopy

\section{What do we know about the peripheral nerve injury?}

Peripheral nerve injury is an important clinical problem, which has only limited number of treatment options. It often occurs due to mechanical traumas and rarely as a result of surgical resection of tumors. ${ }^{1}$ These injuries result in the damage or loss of musculoskeletal system, blood vessel, nerves, and basal membrane. ${ }^{2,3}$ Although some of the damage regenerates spontaneously, some severe traumatic damages result in the loss of motor, auditory, and autonomic functions. ${ }^{2,3}$

Although there is no complete improvement in a majority of traumas, the amount of improvement may vary according to nerve type, grade of injury, and amount of fibrosis. Seddon ${ }^{6}$ and Sunderland ${ }^{5}$ demonstrated two basic classifications to scale the severity of the damage accepted today. Seddon ${ }^{6}$ classified the nerve injuries into three groups: neuropraxia, axonotmesis, and neurotmesis, and Sunderland ${ }^{5}$ further expanded the Seddon's classification ${ }^{6}$ to five degrees according to the damage grades of the tissues and the type of trauma. Sunderland's ${ }^{5}$ first- degree injury type 
is equivalent to Seddon's ${ }^{6}$ neuropraxia type injury, and only temporary transient loss of axonal integrity is not impaired. Sunderland's ${ }^{5}$ second-degree injury type is equivalent to Seddon's ${ }^{6}$ axonotmesis type injury. In this type of injury, there is no axonal integrity, but the endoneurium remains intact. Axonal regeneration is easy due to the presence of the endoneurium. Sunderland's ${ }^{5}$ third- degree injury type refers to injuries sustained in the axon, myelin sheath, and endoneurium but the perineum remains intact. Sunderland's ${ }^{5}$ fourth- degree injury type refers to injuries that occur in the axon, myelin sheath, endoneurium, and perineurium, and the nerve endurance is only provided by the epineurium. Spontaneous healing is not possible. Sunderland's ${ }^{5}$ fifth- degree injury type is equivalent to the neurotmesis type injury of Seddon's classification, ${ }^{6}$ which means that the nerve has been completely cut off and a complete functional loss has occurred. Spontaneous healing is not possible and surgical intervention is required. ${ }^{4-6}$

Current treatment modalities for peripheral nerve injuries are autologous nerve transplantation from sural, saphenous, or medial cutaneous nerves. ${ }^{7}$ It has been reported that the autologous nerve transplantation has fully recovered sensory restorations, whereas motor functions are recovered at a maximum of $40 \%$ level. Complications related to autograft include loss of function (motor and/or sensory), insufficient donor nerve tissue, and donor site morbidity. ${ }^{8,9}$ It is important to understand how nerve tissue repairs itself spontaneously, partly, to develop a repair strategy for greater damage.

\section{Events after the injury}

First studies on peripheral nerve damage are based on the experiments conducted by Augustus Waller in 1850 on the glossopharyngeal and hypoglossal nerves of frogs. Waller tried to observe the postdamage events on axons and tried to explain in his own words that a great number of small chambers were formed on the distal part of the peripheral nerve and Schwann cells lost their white substance (myelin sheaths). ${ }^{10}$ In this century, this process that we call "Wallerian degeneration" corresponds to inflammatory response that occurs in the peripheral nerve as a result of rupture or damage. A great number of genes and proteins (neurotrophic factors, cytokines, and cell adhesion molecules) take charge in all stages of Wallerian degeneration in a coordinated way. ${ }^{11,12}$ The inflammatory process after the peripheral nerve damage influences nerve repair in a positive way. Immunocytochemical analyses have confirmed that after the sciatic nerve damage, $\mathrm{T}$ cells and macrophages migrate to the damage area in 2 days and they expand to the distal part in 4 days. ${ }^{11-15}$ First, Wallerian degeneration starts with the destruction and degeneration of axoplasm and axolemma, and it is completed within 24 hours in small nerves and within 48 hours in greater nerves. After damage, intracellular and extracellular calcium concentration increase directly proportionally with the severity of damage. ${ }^{16,17}$ In in vitro study, increased calcium concentration has been shown to be a significant suppressive factor for the survival of Schwann cells. ${ }^{18}$ Axon destruction that starts with the flow of axonal protease and calcium continues with the help of various intrinsic factors.

As an early period response to axonal destruction, myelin protein synthesis is downregulated by Schwann cells. ${ }^{19,20}$ Immunohistochemical and in situ hybridization studies have shown that Schwann cells are the main source of early cytokine response. ${ }^{15,21,22}$ Later, in their study, Lin et $\mathrm{al}^{23}$ have shown that inflammatory mediators such as TNF-ALFA-IL-6, IL-1BETA, MCP-1, Inos, and COX-2 are released not only from Schwann cells but also from glia cells, and after the nerve damage, nitric oxide (NO) inhibitors and anti-inflammatory cytokines save retinal ganglion cells from apoptosis by inhibiting microbial activation. With the discovery of Wallerian degeneration slow (WLDs) mutant mice in 1989, an important step has been taken to enlighten the nature of Wallerian degeneration. ${ }^{24}$ While axon degeneration is delayed for longer than 2 weeks in WLDs mice, this process takes only 1.5 days in wild-type mice. ${ }^{25}$ Studies on WLDs have shown that NMNAT and SARM-1 have significant roles in Wallerian degeneration. ${ }^{26-28}$

The pathological changes that occur in most peripheral neuropathies show a great deal of similarity. After removal of the above-mentioned myelin and axon residues in any active neuropathy, the loss of myelinated axons and increased endogenous collagen are observed. ${ }^{29}$

Results of studies conducted in our laboratory show the remarkable decrease in myelin sheath thickness of axons and axon diameter (Figure 1).

In electron microscopic sections, newly formed myelinated and unmyelinated axons are noted in damaged nerves (Figure 2).

In the light of all this information, it is known that Wallerian degeneration is important for postdamage nerve repair and mediates protective response formation under damage. Axonal fragmentation, which initiates Wallerian 


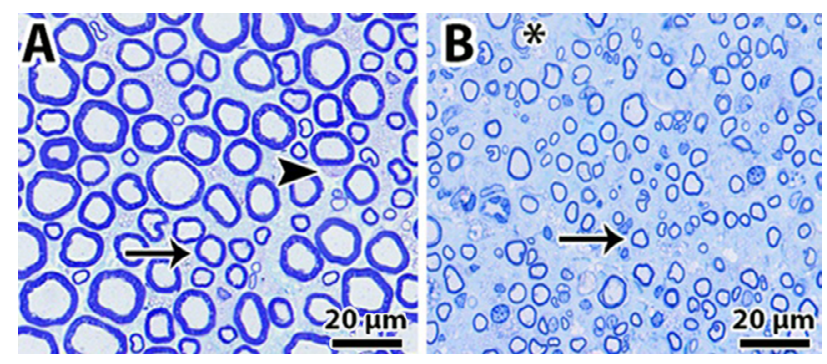

Figure I The light micrograph shows the Toluidine blue staining of the rat sciatic nerve in 500-nm resin-embedded sections.

Notes: (A) Normal peripheral nerve view with tightly packed nerves in normal axon diameter. (B) The view of the crushed nerve 30 days after injury. Abundant number of newly formed and small axons is observed in response to nerve damage. Wallerian degeneration and macrophage-mediated phagocytosis stages have been completed and nerve self-repair initiated. Arrow, myelinated axon; arrowhead, Schwann cell; asterisk, in some of the nerves, the myelin appears to consist of two separate rings. This is caused by the section passing through a Schmidt-Lanterman cleft.
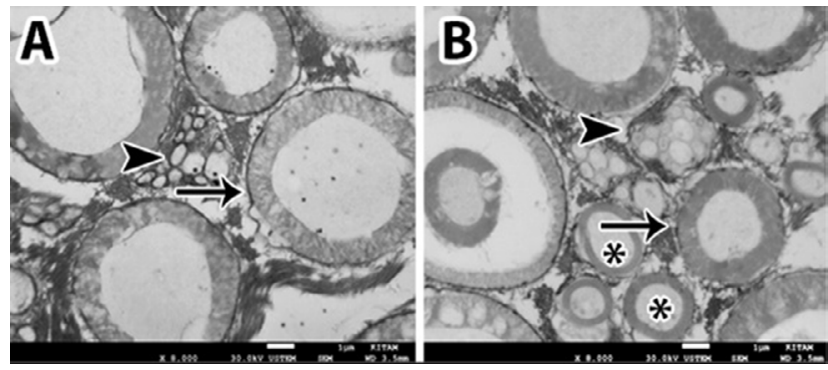

Figure 2 The electron microscopic micrograph indicates the sciatic nerve distal to the nerve crush site from a crush-injured rat.

Notes: (A) Normal peripheral nerve. (B) The view of the crushed nerve 30 days after injury. Sections were stained with lead citrate and uranyl acetate. Arrow, myelinated axon; arrowhead, unmyelinated axon; asterisk, newly formed myelinated axons. Bar indicates I mm length.

degeneration, starts with the mediation of first calcium flow and then calpain activation. ${ }^{30}$ After axonal fragmentation, inflammatory cells of the complement system, chemokines, cytokines and signaling pathways are activated. These factors participate in fragmentation and axonal regeneration, and there are a great number of studies conducted on the roles of these factors. ${ }^{31-42}$

Knowing the order of the events that take place after damage and the effect mechanisms of the factors in charge and thus understanding Wallerian degeneration are important for clarifying the most suitable treatment methods.

\section{Structure, synthesis, and characteristics of melatonin}

Melatonin, also known as $N$-acetyl-5-methoxytryptamine, is synthesized by the pineal gland product, which has basic functions such as the regulation of immune system, regulation of pituitary hormones, and photoperiod adaptation. ${ }^{43,44}$
Melatonin is not synthesized in the fetal brain and maternal melatonin enters the fetal circulation through placenta. ${ }^{45}$ Tryptophan acts as the initiator of melatonin biosynthesis, and it is taken from the circulation and turned into serotonin. Serotonin is later turned into $\mathrm{N}$-acetylserotonin through AANAT enzyme, and $N$-acetylserotonin is further metabolized to melatonin through HIOMT enzyme. ${ }^{46}$

Melatonin given intravenously is first hydroxylated in the liver by cytochrome P450 monooxygenases, and then it is conjugated with sulfate to form 6-sulfatoxymelatonin. . $^{47,48}$ Melatonin is also metabolized to kinuramine derivatives with oxidative pyrrole ring separation. ${ }^{49}$ Primary separation product is either arylamine formamidase or $N 1$-acetylN2-formyl-5-methoxykynuramine (AFMK) deformalized to $N 1$-acetyl-5-methoxykynuramine by hemoperoxidase. ${ }^{50,51}$ Evidences have suggested that pyrrole ring separation contributes to about one third of total melatonin catabolism; however, this rate can be much higher in some tissues. AFMK has been put forward to be the primary and major active metabolite of melatonin. ${ }^{51}$

Although melatonin is primarily known as an indole synthesized from the pineal gland, other organs have the feature to synthesize melatonin, which has local influences. In addition to its transducer effect on circadian rhythm, its other functions have been clarified in the past decades such as direct free radical scavenging and the regulation of the genes of antioxidant enzymes. ${ }^{52-56}$ Similar to the studies on the antioxidant properties of melatonin, its cell protective effect and potential disease-preventing characteristics have also been studied frequently. ${ }^{57-61}$ Currently, the "oxidant scavenger" effect of melatonin on radical and nonradical agents has been proven. ${ }^{58-62}$

In addition, current studies indicate that melatonin production can occur in several sites such as astrocytes, the neuron in the brain. ${ }^{63}$ In this context, melatonin synthesis is correlated with mitochondrial alterations. Mitochondria and chloroplasts can be considered the primary site of melatonin production in some cells such as neuron and glia. ${ }^{63,64}$

\section{The promoting effect of melatonin on peripheral nerve injury: general overview}

Peripheral nerve trauma is common and repair generally occurs with scar tissue formation around the injury area. ${ }^{65}$ Scar tissue formation leads to a block in neural conduction by creating a mechanical barrier for axonal regeneration. If scar formation can be prevented, the development of axonal extensions and so the regeneration process will 
accelerate. ${ }^{66,67}$ Some agents have been used for previous in vivo experimental studies for this purpose. ${ }^{67-69}$ Although many experimental and clinical studies were performed to obtain the outcomes of peripheral nerve injury, the methods for improving peripheral nerve damage are limited in the literature. $^{70-73}$

Microsurgery procedure is of great importance in peripheral nerve regeneration. In addition, regeneration procedure also depends on many factors such as location of injury and duration of the regeneration. ${ }^{74}$ Especially, current data obtained from experimental studies have shown that pharmacological agents has a role in the repair mechanism. ${ }^{75-77}$ In this context, it has been suggested that melatonin, hyaluronic acid, methylprednisolone, and tacrolimus (FK506) are among the most used topical agents to accelerate the repair process by suppression of fibroblast proliferation in the damaged area. Hence, scar formation reduces in the nerve injury. ${ }^{75}$ Melatonin has many physiological roles in vivo such as pharmacological modulation of circadian rhythm, regulation of blood pressure, and free radicals scavenging as mentioned above. Especially, melatonin has an active role in healing nerve damage because of its broad-spectrum antioxidant properties and its ability to be a powerful inhibitor of apoptosis. Hence, it is an alternative agent to prevent the scar formation around the damage area. ${ }^{79,80}$ In the peripheral nervous system, melatonin is effective on axon sprouting after trauma. ${ }^{81}$ From another point of view, the regeneration process is associated with the balance between Schwann cell proliferation and scar tissue formation. ${ }^{82,83}$

Several studies showed that melatonin supplement decrease the scar formation in the nerve injury through inhibiting the collagen production. ${ }^{73,78,81,84}$ Similarly, Shokouhi et $\mathrm{al}^{85}$ reported that low-dose melatonin supplement could decrease the myelin damage and axonal alterations in the peripheral nerve. In addition, Stavisky et $\mathrm{al}^{86}$ pointed out that melatonin also plays a major role in the healing of a highly injured sciatic nerve by plasmalemma fusion. While studies on the effect of melatonin on the regeneration often deal with oxidative stress mechanisms, the effects of melatonin can be elaborated with molecular researches.

\section{Antioxidant effects of melatonin on regeneration: key points for oxidative stress mechanisms}

The role of antioxidants in the posttraumatic recovery of the damage in the peripheral and central nervous systems cannot be denied. After a neuronal trauma, it is believed that the primary cause of peripheral nerve injury is lipid peroxidation, which progresses along the nerve fibers and is induced by free radicals. Therefore, the primary target of antioxidants is thought to be the scavenging of free radicals in the repair of degeneration. ${ }^{87,88}$ Some researchers reported that melatonin, which is a pineal hormone, has an neuroprotective and free radical scavenging effect on the peripheral nervous system. ${ }^{76,77,86,89,90}$ Because of the lipid solubility of melatonin, it easily penetrates the cell membrane and organelles. In addition, an antioxidant can penetrate the mitochondria of the cell. In this respect, it can also protect the mitochondria from oxidative damage. ${ }^{91}$ Melatonin supplementation is an effective antioxidant in the development of the peripheral nervous system. Especially, it has been proven to have an important role in the inhibition of axonal sprouting and collagen accumulation. ${ }^{92,93}$ Qiu et $\mathrm{al}^{65}$ suggested that oxidative stress and free radical-induced lipid peroxidation negatively affect the repair of peripheral nerve damage. After peripheral nerve damage, melatonin provides oxidative action by stimulating superoxide dismutase enzyme, an important antioxidative enzyme. Superoxide dismutase enzyme acts as a redox regulator. ${ }^{94}$ Melatonin stimulates antioxidant enzymes by inhibiting the posttraumatic polymorphonuclear infiltration. ${ }^{95,96}$ In addition, melatonin can reduce oxidative damage by preventing the levels of catalase, peroxidase, and ascorbate peroxidase such as superoxide dismutase (Figure 3)..$^{97-99}$

Nerve tissue does not contain highly oxidative defense mechanisms, and thus, lipid peroxidation negatively affects the integrity of the neuronal structure by disrupting membrane-binding receptors and enzymes. Melatonin can easily pass the physiological barriers in the lipid and aqueous environments. ${ }^{79}$ Melatonin can enter into nucleus, and therefore, it protects DNA, intracellular proteins, and

\section{Melatonin supplement \\ Receptor independent}

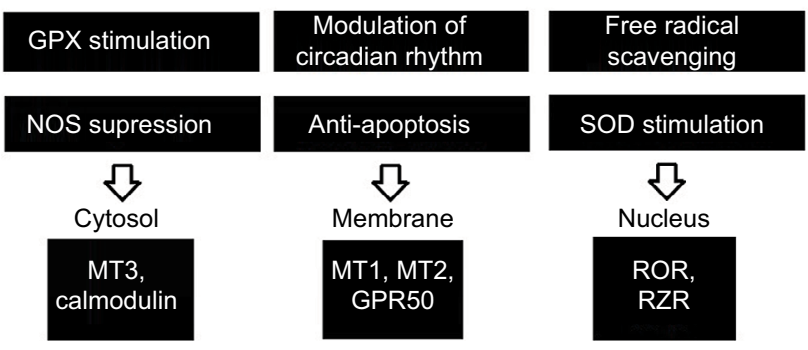

Figure 3 The schema represents the receptor-dependent and receptorindependent effects of melatonin.

Notes: This figure shows the effect of melatonin and its metabolites on scavenging the reactive oxygen products through nonreceptor-independent actions.

Abbreviations: MTI, metallothionein I; SOD, superoxide dismutase. 
membranes lipids from oxidative stress. ${ }^{91}$ Melatonin reduces the oxidative stress by affecting NO and NO synthase after peripheral axotomy. It is known that melatonin exerts antioxidant effects by mimicking the effects of calcium channel blockers. ${ }^{92}$ It is believed that melatonin is an electron donor for the detoxification of free radicals. Thus, it protects the sciatic nerve from ischemia via reducing lipid peroxidation. ${ }^{100,101}$ In addition, according to the study by Atik et al, ${ }^{92}$ melatonin has a direct effect on the independent receptors of toxic radicals. Therefore, it has high potential affinity for peroxyl and hydroxyl radicals via receptor for inactivation of free radicals. It has antioxidant properties with its affinity to receptors (Figure 4). ${ }^{102}$

Melatonin has antioxidant, circadian rhythm regulator, and immunoregulator properties as well as anti-inflammatory properties. ${ }^{103-105}$ The anti-inflammatory effect of melatonin reduces the formation of free radicals accompanying inflammatory response. ${ }^{105}$ Melatonin reduces inflammatory mediators and activates the antioxidant enzymes by signal transduction pathways. Especially, the nuclear factor 2 (Nrf2) expression has an important role in the activation of antioxidant enzymes such as superoxide dismutase, catalase, and glutathione peroxidase, and it is believed that melatonin affects the antioxidant enzymes with $\mathrm{Nrf} 2$ signaling pathway (Figure 5). ${ }^{51,103,106}$ When the antioxidant effects of melatonin are examined in general, it can be seen that there is a fairly wide spectrum of antioxidants

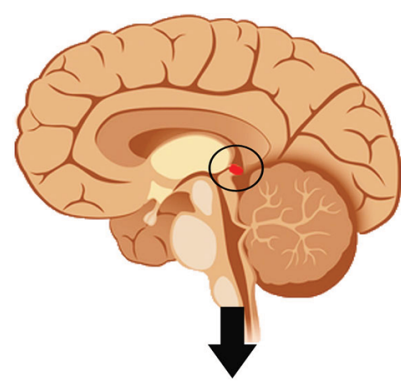

Melatonin secretion

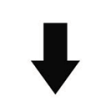

Scavenging of free radicals
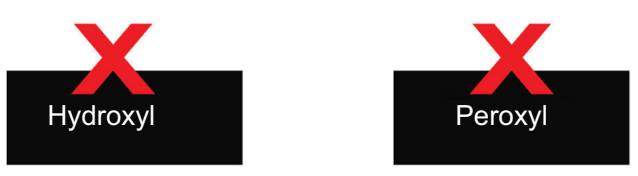

Figure 4 Melatonin is an endogenously synthesized and secreted hormone by the pineal gland and possesses intense antioxidant activity. including reduction of synthesis of adhesion molecules and pro-inflammatory cytokines. ${ }^{107}$ Because melatonin has no pro-oxidative activity, the melatonin molecule is not easily oxidized, does not undergo autooxidation, and does not enter the hydroxyl radical-generating reactions in the redox cycle. More importantly, unlike other antioxidants, melatonin does not show toxic effects at very high doses (300 mg/day) and even for as long as 5 years. ${ }^{108}$

\section{Melatonin and Schwann cells: extracellular signal-regulated kinase (ERK) pathway}

After injury, a number of endogenous factors have been identified that are effective in maintaining the vitality of axons and axonal growth. ${ }^{109,110}$ Schwann cells play a key role in peripheral nerve regeneration by regulating axonal proliferation. ${ }^{111}$ In addition, Schwann cells secrete various neurotrophic factors such as bFGF and nerve growth factor, which play a major role in regeneration of peripheral nervous system and development. ${ }^{112,113}$ In addition, bGFG and TGF- $\beta$ are important for Schwann cell activity. Turgut et $\mathrm{al}^{114}$ studied the expression of these growth factors, which have important role in the control of neuroma formation and collagen accumulation in rats that underwent pinealectomy. Also this study showed that melatonin supplementation suppressed proximal neuroma and contributed to repair mechanism.

Metallothionein 1 melatonin receptor, which depends on the phosphorylation of ERK1/2, plays a role in the proliferative effect of melatonin on Schwann cells (Figure 6). ${ }^{115-117}$ Harrisingh et al $^{118}$ suggested that Schwann cells stimulated by "damage signals" could be considered as a regenerative cell type in response to peripheral nerve injury. In this context, Ras/Raf/mitogen-activated protein kinase/ERK signaling regulates the differentiation of Schwann cells. ${ }^{118}$ In addition, ERK/MAPK signaling activity stimulates Schwann cell differentiation. Syed et $\mathrm{al}^{119}$ studied the quantitative model of ERK/MAPK activity and found that lower levels induce myelination, whereas higher levels induce Schwann cell differentiation and proliferation. In addition, ERK/MAPK activity is needed at basal level for the differentiation of the progenitors. ${ }^{119}$ Similarly, Seo et al ${ }^{120}$ suggested that an increase in the ERK1/2 activation promotes the Schwann cell proliferation, and thus, it is crucial in the repair of sciatic nerve. This point of view shows that exogenous melatonin administration can promote the Schwann cell proliferation and also increase the reinnervations. ${ }^{121}$ 


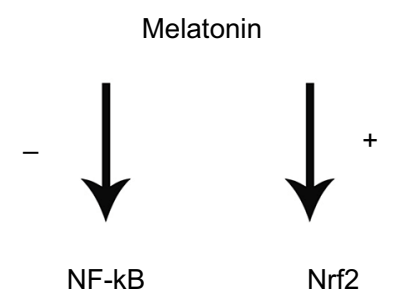

Cytoplasm

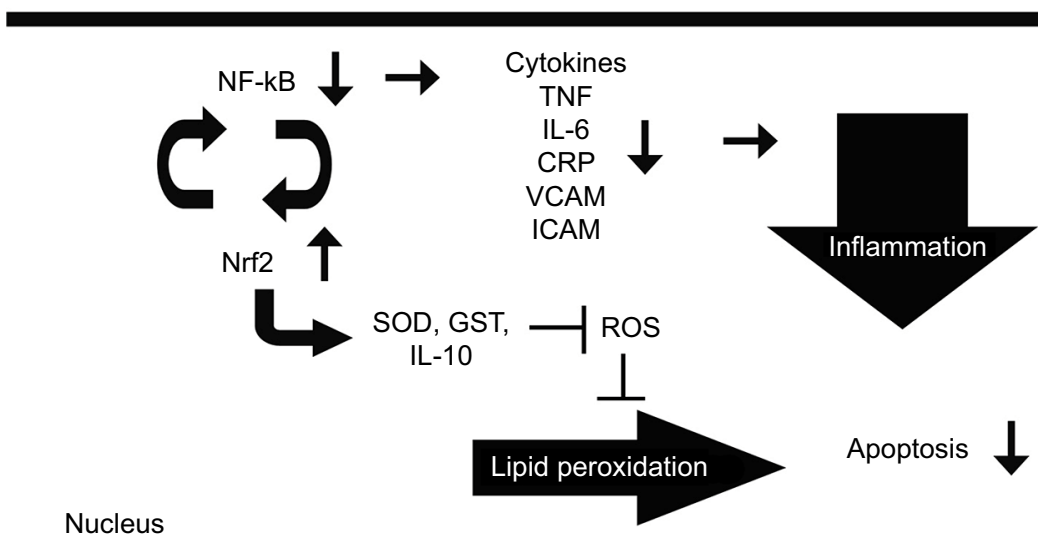

Figure 5 Schematic representation shows the role of NF-kB and Nrf2 pathways on the effect of melatonin on the injury.

Notes: Melatonin induces the antioxidant protection. ROS increases the NF-kB transcription and cytokines. In addition, relationship between inflammation and lipid peroxidation is explained in the schema and the role of them on apoptosis.

Abbreviations: IL, interleukin; NF-kB, nuclear factor-kB; Nrf2, nuclear factor 2; ROS, reactive oxygen species; TNF, tumor necrosis factor; ICAM, intercellular adhesion molecule; SOD, superoxide dismutase; GST, glutathione S-transferase.

\section{Controversies on dose-dependent effects of melatonin on regeneration}

After trauma, an increase in lipid peroxidation occurs. Significant increases in lipid peroxidation have been shown at 1 st, 24th, and 48th hours in studies performed. ${ }^{122}$ It was determined that the rate of peroxidation returned to its preinjury level, and melatonin had maximal chronic neuroprotective effect after 48 hours. ${ }^{123}$ In addition, it was suggested that melatonin is neuroprotective at doses of $1-50 \mathrm{mg} / \mathrm{kg} .{ }^{85,114,122}$ Especially, Shokouhi et al ${ }^{85}$ reported that melatonin at $50 \mathrm{mg} / \mathrm{kg}$ dose has a potentially positive effect on preserving the neural fibers. Similarly, Kaya et al ${ }^{124,125}$ studied the effect of melatonin at $50 \mathrm{mg} / \mathrm{kg}$ dose on nerve injury.

In clinical studies, melatonin doses range from 0.1 to 2,000 mg. ${ }^{22}$ More than $0.5 \mathrm{mg}$ of melatonin dosage shows pharmacologically therapeutic effect. ${ }^{126,127}$ Rogerio et al ${ }^{128}$ investigated the effect of melatonin on motor neuron death in the spinal cord after sciatic nerve injury in their study and compared the doses of $1,5,10$, and $50 \mathrm{mg} / \mathrm{kg}$ of melatonin for this purpose. They reported that $1-50 \mathrm{mg} / \mathrm{kg}$ melatonin is effective in decreasing the neuronal death. In addition, the neuroprotective effect is fully active even at the lowest dose, although toxic effects may possibly occur at doses of 50-100 $\mathrm{mg} / \mathrm{kg} .{ }^{128}$ In addition, Cunnane et al ${ }^{129}$ previously studied low doses $(30 \mu \mathrm{g} / 100 \mathrm{~g})$ of melatonin after the pinealectomy process. They reported that melatonin reduced the collagen in the injury area. ${ }^{129}$ However; Atik et $\mathrm{a}^{12}$ suggested that the physiological dose of melatonin could not be sufficient for its beneficial effects. Melatonin shows the receptor-mediated activity at physiological doses. However, pharmacological concentrations of melatonin are required for the receptorindependent activity. ${ }^{130}$ Turgut et al ${ }^{131}$ reported the positive effect of melatonin on reducing the neuroma formation in the sciatic nerve injury by enhancing axonal regeneration.

Shokouhi et al ${ }^{85}$ compared the effects of low $(10 \mathrm{mg} / \mathrm{kg})$ and high dose $(50 \mathrm{mg} / \mathrm{kg})$ of melatonin on lipid peroxidation in the experimental sciatic nerve injury. In this study, they aimed to assess the dose-dependent neuroprotective and antioxidant activity of melatonin on injury. They found the beneficial effects of high-dose melatonin on axonal damage compared to that of low-dose melatonin. ${ }^{85}$ Contrarily, Gul et a ${ }^{132}$ reported no dose-dependent effect of melatonin in the decreasing of lipid peroxidation in the sciatic nerve-injured rat after spinal cord clamping. Rogerio et a ${ }^{128}$ investigated the effect of melatonin at doses of $1,5,10$, and $50 \mathrm{mg} / \mathrm{kg}$ on 


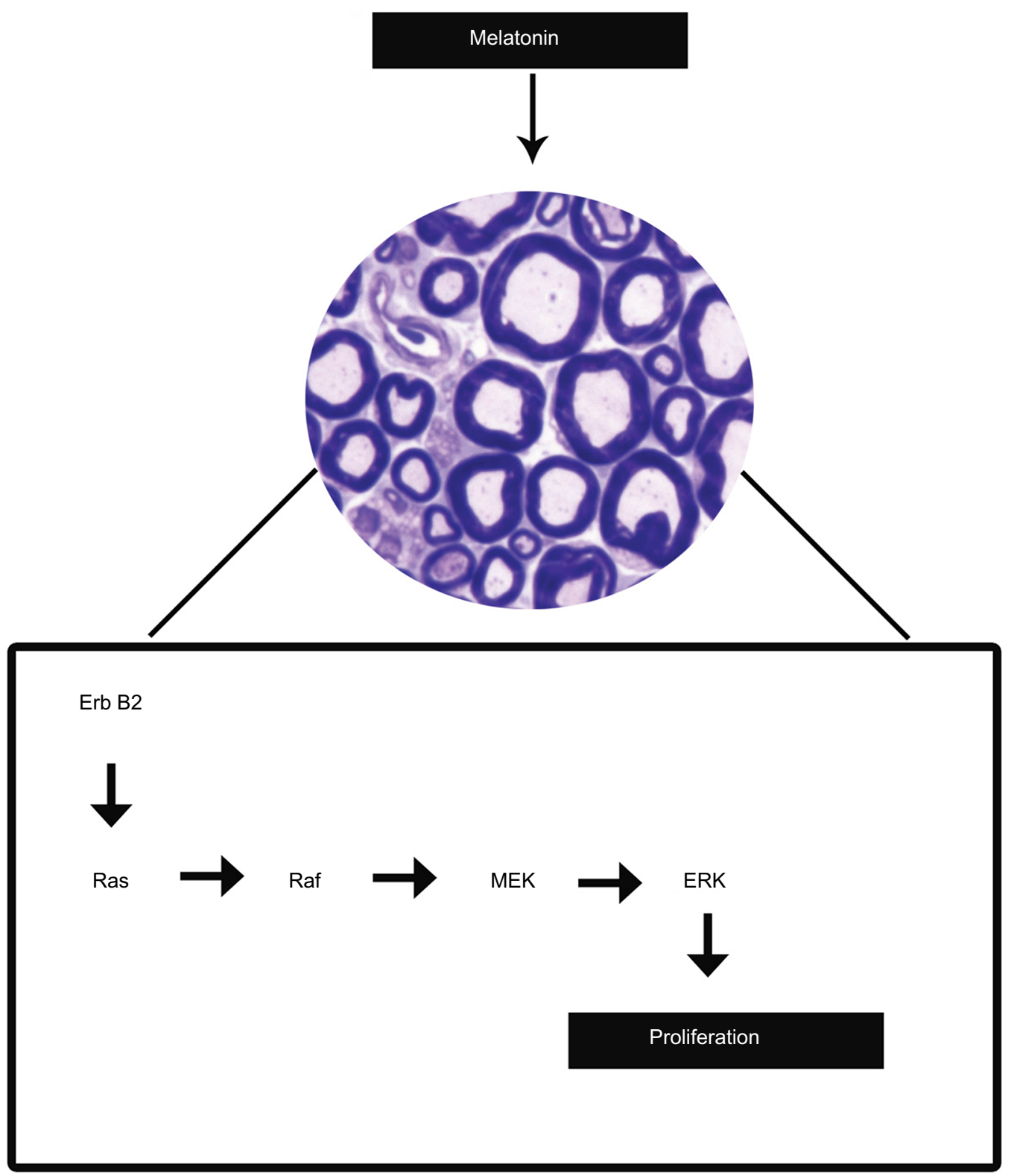

Figure 6 Schematic representation indicates the role of ErbB2 receptor on inducing the Schwann cell proliferation through Ras/Raf/MEK/ERK pathway. Abbreviations: ERK, extracellular signal-regulated kinase; MEK, mitogen-activated protein kinase.

sciatic nerve injury and observed the significant decrease in motor neuron death in the melatonin-treated groups. According to this study, administration of the low dose of melatonin is more effective for the neuronal survival rather than a high concentration of melatonin. ${ }^{128}$ At this point, it can be said that the high dose of melatonin causes the toxic effect. Another study conducted by Chang et $\mathrm{al}^{100}$ suggested that melatonin decreased the expression of NO synthase in the hypoglossal nerve injury and a dose-dependent neuroprotective effect of it is due to antioxidant properties.
It is important to determine the minimum dose of melatonin in peripheral nerve regeneration. Ulugol et $\mathrm{al}^{133}$ demonstrated that high dose of melatonin prevented thermal hyperalgesia caused by nerve damage. In mice, intracerebroventricular and intraperitoneal administration of melatonin prevented the hyperalgesia by L-arginine-NO and opioidergic pathways in the neuropathic pain. However, it had no effect on the mechanical allodynia. ${ }^{133}$ Opioidergic and gammaaminobutyric acid ergic systems have an important role in the effects of melatonin. ${ }^{134,135}$ Similarly, Mantovani et $\mathrm{al}^{135}$ 
showed the antidepressant effect of melatonin in the mouse through L-arginine-NO pathway and $N$-methyl D-aspartate receptors. Also it can be concluded that useful doses of melatonin contribute to the repair of peripheral nerve injury by attenuating the oxidative stress mechanisms.

\section{Comparison of beneficial effects of melatonin and some agents on nerve repair: summary of current studies}

In recent years, several experimental studies focusing on the effect of melatonin on peripheral nerve injury have been performed. In addition, many studies have compared the regenerative effect of melatonin with other antioxidants and have introduced new combinations of treatments. The formation of collagen scar tissue in peripheral nerve injury is a clinically important problem. Scar formation blocks the axons from sprouting into the appropriate distal fascicles, thus delaying the regeneration process. Control of the collagen accumulation in the neuroma formation was experimented using various chemical and physiological methods, but a functional success could not be achieved. ${ }^{131}$ In another study by Turgut et al, ${ }^{81}$ the effect of exogenous melatonin administration on scar formation was examined in the damaged nerves. After pinealectomy, they observed fibroblast proliferation by using stereological techniques. In addition, after melatonin administration, regenerating axons were observed at the proximal nerve ends. They demonstrated the inhibitory effect of melatonin on collagen accumulation. Furthermore, they suggested that surgical pinealectomy causes an increase in the collagen accumulation. However, melatonin administration suppresses this accumulation after pinealectomy. ${ }^{81}$ The role of TGF- $\beta$ and bFGF collagen production and thus scar formation is known. In this regard, another study by Turgut et $\mathrm{al}^{114}$ on pinealectomized rats revealed that expression of TGF- $\beta 1$ and bFGF was suppressed by melatonin using immunohistochemical methods. In a study of pinealectomized chickens, Turgut et $\mathrm{al}^{136}$ also examined the neuroprotective effects of melatonin. Neonatal pinealectomized chickens suggested negative effects on sciatic nerves. They showed that melatonin has a regulatory effect on collagen content. $^{136}$

Stavisky et $\mathrm{al}^{86}$ investigated the effects of cyclosporine A, glial-derived neurotrophic factor, and methylprednisolone, as well as the effects of melatonin on polyethylene glycol-induced repair in the sciatic damage. They measured conduction of compound action potentials in the lesion area after polyethylene glycol fusion. In in vivo and in vitro preparations, a significant increase in the improvement for melatonin-administrated group was determined compared to control Krebs saline. They suggested that in combination with polyethylene glycol fusion, melatonin provides rapid repair of crush-type injuries of the spinal cord. ${ }^{86}$ Similarly, Daglioglu et al ${ }^{137}$ designed a study on beneficial effects of melatonin at appropriate doses on peripheral nerve injury. They suggested that melatonin administration could be successful in the treatment of peripheral nerve injury. ${ }^{137}$ Moreover, Zencirci et $\mathrm{al}^{138}$ examined the functional effects of melatonin on sciatic nerve crush injury. The researchers applied melatonin at doses of 5 and $20 \mathrm{mg} / \mathrm{kg}$ for 21 days. In this study, melatonin showed a positive effect on the sciatic function index. In addition, while melatonin increases the conduction velocities, it decreases latency according to the study by Zencirci et al, ${ }^{138}$ and the regenerative effect of the melatonin has been shown to be dose independent. Possibly the application of melatonin at 5 and $20 \mathrm{mg} / \mathrm{kg}$ intraperitoneally may show similar antioxidant effect. ${ }^{138}$ However, Atik et $\mathrm{al}^{92}$ suggested that beneficial effects of melatonin in nerve regeneration could be seen at physiological doses. Kaplan et al ${ }^{83}$ studied the effects of intraperitoneal melatonin administration after intraoperative platelet gel on sciatic nerve regeneration. Platelet gel application had a positive effect on nerve regeneration, but platelet gel application did not show the same effect when combined with melatonin. Administration of melatonin alone or in combination with platelet gel did not show any positive effect on nerve regeneration. This failure of regeneration reveals that melatonin does not play a role in inhibiting collagen formation. ${ }^{83}$ In other respects, $30 \mu \mathrm{g} / 100 \mathrm{~g}$ melatonin was used in this study. ${ }^{81}$ This dose may be inadequate to show antioxidant activity of melatonin. However, Kaya et $\mathrm{al}^{71}$ suggested that administration of $50 \mathrm{mg} / \mathrm{kg}$ melatonin showed improvement effects on nerve injury reducing oxidative stress.

Yanilmaz et $\mathrm{al}^{73}$ suggest that some agents may have a positive effect on recovery after nerve palsy. In this respect, they examined the effect of melatonin, aminoguanidine, and methylprednisolone on facial nerve damage. They observed a decrease in the myelin debris of melatonin-administrated group. This study showed an increase in regeneration of the facial nerve in aminoguanidine- and melatonin-administrated groups; however, methylprednisolone was insufficient to prevent myelin degeneration. In particular, most efficient agent was aminoguanidine on reducing the collagen accumulation and preventing degeneration. ${ }^{73}$ In this context, the appropriate dose may not have been administered for the neuroprotective 
effect of melatonin on the facial nerve. Onger et $\mathrm{al}^{76}$ investigated the effects of $50 \mathrm{mg} / \mathrm{kg}$ melatonin on sciatic nerve damage compared to the effects of acetyl-L-carnitine $(50 \mathrm{mg} / \mathrm{kg}$ ) and leptin $(1 \mathrm{mg} / \mathrm{kg})$. On the other hand, Onger et $\mathrm{al}^{77}$ studied the peripheral nerve damage in the obese rats using the same antioxidant agents. According to their data, melatonin has no regenerative effect on obese rats. Contrarily, leptin and acetylL-carnitine could stimulate the myelination and regeneration in the sciatic nerve injury. Melatonin has anti-obesity effect. In this context, they claimed that melatonin led to decrease in the white adipose tissue mass and increase in the activity of brown adipose, thus energy requirement could not meet for regeneration. In addition, adequate stem cells cannot be obtained from the white fat tissue. However, acetyl-L-carnitine accelerates the pass of long-chain fatty acids through the inner membrane of mitochondria and has a function in the requiring neuronal energy after nerve injury. ${ }^{77}$

In a recent study, Salehi et al ${ }^{139}$ aimed to increase the efficiency of regeneration by allogenic Schwann cell transplantation using a biologic transporter. In this study, a conduit made of polyurethane and gelatin nanofibers was prepared and filled in with platelet-rich plasma and melatonin. They observed that this conduit enhanced the regeneration of the damaged site. However, functional success has not been achieved in this method as far as autograft is applied. ${ }^{139}$

As a result, studies in recent years have focused on introducing new methods, including the local application of antioxidants, rather than the systemic application of them to accelerate the regeneration process in nerve crush injury.

\section{Conclusion}

Peripheral nerve injuries are still among the vital clinical issues, and thus, the research for advanced knowledge about this condition and its treatment still continues. ${ }^{92}$ Regarding this, some studies demonstrate that pineal neurohormone melatonin has effects on the physiological and histological properties of the nerve tissue, hinting at its effects of antioxidation, analgesia, and free radical scavenging in the degenerative peripheral nerve disorders. It is acknowledged that melatonin has beneficial effects on the length of the axons, the sprouting after the damage to peripheral nerves. ${ }^{93,96,140}$ Nevertheless, some studies indicate the hazardous effects of melatonin on peripheral nerves. ${ }^{141,142}$ To shed light on the beneficial or detrimental effects of melatonin treatment in low and high doses, further clinical and experimental studies should be performed.

\section{Disclosure}

The authors report no conflicts of interest in this work.

\section{References}

1. Hasegawa T, Kuroda M. A new role of uric acid as an antioxidant in human plasma. Rinsho Byori. 1989;37(9):1020-1027.

2. Grogan BF, Hsu JR. Volumetric muscle loss. J Am Acad Orthop Surg. 2011;19(1):35-37.

3. Grasman JM, Zayas MJ, Page RL, Pins GD. Biomimetic scaffolds for regeneration of volumetric muscle loss in skeletal muscle injuries. Acta Biomater. 2015;25:2-15.

4. Dagum AB. Peripheral nerve regeneration, repair, and grafting. J Hand Ther. 1998;11(2):111-117.

5. Sunderland S. A classification of peripheral nerve injuries producing loss of function. Brain. 1951;74(4):491-516.

6. Seddon HJ. Three types of nerve injuries. Brain. 1943;66(4):237-288.

7. Ichihara S, Inada Y, Nakamura T. Artificial nerve tubes and their application for repair of peripheral nerve injury: an update of current concepts. Injury. 2008;39(4):29-39.

8. Allodi I, Udina E, Navarro X. Specificity of peripheral nerve regeneration: interactions at the axon level. Prog Neurobiol. 2012;98(1):16-37.

9. Sivak WN, White JD, Bliley JM, et al. Delivery of chondroitinase $\mathrm{ABC}$ and glial cell line-derived neurotrophic factor from silk fibroin conduits enhances peripheral nerve regeneration. J Tissue Eng Regen Med. 2014;11(3):733-742.

10. Waller A. Experiments on the section of the glossopharyngeal and hypoglossal nerves of the frog, and observations of the alterations produced thereby in the structure of their primitive fibres. Philos Trans $R$ Soc Lond. 1850;140:423-429.

11. Rotshenker S, Aamar S, Barak V. Interleukin-1 activity inlesioned peripheral nerve. J Neuroimmunol. 1992;39(1-2):75-80.

12. Reicherd F, Rotshenker S. Deficient activation of microglia during optic nerve regeneration. J Neuroimmunol. 1996;70:153-161.

13. Brück W. The role of macrophages in Wallerian degeneration. Brain Pathol. 1997;7(2):741-752.

14. Stoll G, Jander S. The role of the microglia and macrophages in the pathophysiology of the CNS. Prog Neurobiol. 1999;58(3):233-247.

15. Jander S, Pohl J, Gillen C, Stoll G. Differential expression of interleukin-10 Mrna in Wallerian degeneration and immune mediated inflamation of the rat peripheral nervous system. $J$ Neurosci Res. 1996;43(2):254-259.

16. LoPachin RM, Lehning EJ. Mechanism of calcium entry during axon injury and degeneration. Toxicol Appl Pharmacol. 1997;143(2):233-244.

17. Manev H, Favaron M, Guidotti A, Costa E. Delayed increase of Ca2p influx elicited by glutamate: role in neuronal death. Mol Pharmacol. 1989;36(1):106-112.

18. Yang KJ, Yan Y, Zhang LL, et al. Increasing calcium level limits Schwann cell numbers in vitro following peripheral nerve injury. J Reconstr Microsurg. 2017;33(6):435-440.

19. Perry VH, Brown MC, Lunn ER, Tree P, Gordon S. Evidence that very slow Wallerian degeneration in C57BL/Ola mice is an intrinsic property of the peripheral nerve. Eur J Neurosci. 1990;2(9):802-808

20. Glass JD, Brushart TM, George EB, Griffin JW. Prolonged survival of transsected nerve fibres in C57BL/Ola mice is an intrinsic characteristic of the axon. J Neurocytol. 1993;22(5):311-321.

21. Bolin LM, Verity AN, Silver JE, Shooter EM, Abrams JS. Interleukin-6 production by schwann cells and induction in sciatic nerve injury. J Neurochem. 1995;64(2):850-858.

22. Bourde O, Kiefer R, Toyka KV, Hartung HP. Quantification of interleukin $6 \mathrm{Mrna}$ in Wallerian degeneration by competititve reverse transcription polymerase chain reaction. J Neuroimmunol. 1996;69(1-2):135-140.

23. Lin SF, Chien JY, Kapupara K, Huang CF, Huang SP. Oroxylin A promotes retinal ganglion cell survival in a rat optic nerve crush model. PLoS One. 2017;12(6): 0178584.

24. Lunn ER, Perry VH, Brown MC, Rosen H, Gordon S. Absence of Wallerian degeneration does not hinder regeneration in peripheral nerve. Eur J Neurosci. 1989;1(1):27-33. 
25. Beirowski B, Adalbert R, Wagner D, et al. The progressive nature of Wallerian degeneration in wild-type and slow Wallerian degeneration (WldS) nerves. BMC Neurosci. 2005;6:6.

26. Gilley J, Coleman MP. Endogenous NMNAT2 is an essential survival factor for maintenance of healthy axons. PLoS Biol. 2010;8(1):e1000300.

27. Osterloh JM,Yang J, RooneyTM, etal. dSarm/Sarm1 is required for activation of an injury-induced axon death pathway. Science. 2012;337(6093): 481-484.

28. Gerdts J, Summers DW, Sasaki Y, DiAntonio A, Milbrandt J. Sarm1mediated axon degeneration requires both SAM and TIR interactions. J Neurosci. 2013;33(33):13569-13580.

29. Lauria G, Lombardi R. Skin biopsy: a new tool for diagnosing peripheral neuropathy. BMJ. 2007;334(7604):1159-1162.

30. Conforti L, Gilley J, Coleman MP. Wallerian degeneration: an emerging axon death pathway linking injury and disease. Nat Rev Neurosci. 2014;15(6):394-409.

31. Perrin FE, Lacroix S, Aviles-Trigueros M, David S. Involvement of monocyte chemoattractant protein-1, macrophage inflammatory protein-1alpha and interleukin-1beta in Wallerian degeneration. Brain. 2005;128(pt 4):854-866.

32. Boivin A, Pineau I, Barrette B, et al. Toll-like receptor signalling is critical for Wallerian degeneration and functional recovery after peripheral nerve injury. $J$ Neurosci. 2017;27(46):12565-12576.

33. Chen ZL, Yu WM, Strickland S. Peripheral regeneration. Annu Rev Neurosci. 2007;30:209-233.

34. Vargas ME, Barres BA. Why is Wallerian degeneration in the CNS so slow? Annu Rev Neurosci. 2007;30:153-179.

35. Camara-Lemarroy CR, Guzman-de la Garza FJ, Fernandez-Garza NE. Molecular inflammatory mediators in peripheral nerve degeneration and regeneration. Neuroimmunomodulation. 2010;17(5):314-324.

36. Bosse F. Extrinsic cellular and molecular mediators of peripheral axonal regeneration. Cell Tissue Res. 2012;349(1):5-14.

37. Napoli I, Noon LA, Ribeiro S, et al. A central role for ERK-signalling pathway in controlling Schwan cell plasticity and peripheral nevre regeneration in vivo. Neuron. 2012;73(4):729-742.

38. Menorca RM, Fussell TS, Elfar JC. Nerve physiology: mechanisms of injury and recovery. Hand Clin. 2013;29(3):317-330.

39. Bastien D, Lacroix S. Cytokine pathways regulating glial and leukocyte function after spinal cord and peripheral nerve injury. Exp Neurol. 2014;258:62-77.

40. Brosius LA, Barres BA. Contrasting the glial response to axon injury in the central and peripheral nervous systems. Dev Cell. 2014;28(1):7-17.

41. DeFrancesco-Lisowitz A, Lindborg JA, Niemi JP, Zigmond RE. The neuroimmunology of degeneration and regeneration in the peripheral nervous system. Neuroscience. 2015;302:174-203.

42. Mietto BS, Mostacada K, Martinez AM. Neurotrauma and inflammation: CNS and PNS responses. Mediators Inflamm. 2015;2015:251204.

43. Reiter RJ. The pineal gland and melatonin in relation to aging: a summary of the theories and of the data. Exp Gerontol. 1995;30(3-4):199-212.

44. Rodriguez C, Mayo JC, Sainz RM, et al. Regulation of antioxidant enzymes: a significant role for melatonin. J Pineal Res. 2004;36(1):1-9.

45. Uyanikgil Y, Baka M, Ateş U, et al. Neuroprotective effects of melatonin upon the offspring cerebellar cortex in the rat model of BCNUinduced cortical dysplasia. Brain Res. 2007;1160:134-144.

46. Axelrod J, Wurtman RJ. Photic and neural control of indoleamine metabolism in the rat pineal gland. Adv Pharmacol. 1968;6(pt A):157-166.

47. Claustrat B, Brun J, Chazot G. The basic physiology and pathophysiology of melatonin. Sleep Med Rev. 2005;9(1):11-24.

48. Skene DJ, Papagiannidou E, Hashemi E, et al. Contribution of CYP1A2 in the hepatic metabolism of melatonin: studies with isolated microsomal preparations and liver slices. J Pineal Res. 2001;31(4):333-342.

49. Hirata F. Melatonin. No Shinkei Geka. 1974;2(3):207-212.

50. Hardeland R, Reiter RJ, Poeggeler B, Tan DX. The significance of the metabolism of the neurohormone melatonin: antioxidative protection and formation of bioactive substances. Neurosci Biobehav Rev. 1993;17(3):347-357.
51. Tan DX, Manchester LC, Terron MP, Flores LJ, Reiter RJ. One molecule, many derivatives: a never-ending interaction of melatonin with reactive oxygen and nitrogen species? J Pineal Res. 2007;42(1): 28-42.

52. Cassone VM. Effects of melatonin on vertebrate circadian systems. Trends Neurosci. 1990;13(11):457-464.

53. Blask DE, Hill SM, Orstead KM, Massa JS. Inhibitory effects of the pineal hormone melatonin and underfeeding during the promotional phase of 7,12 dimethylbenzanthracene-(DMBA)-induced mammary tumorigenesis. J Neural Transm. 1986;67(1-2):125-138.

54. Maestroni GJ, Conti A, Pierpaoli W. Role of the pineal gland in immunity: II. Melatonin enhances the antibody response via an opiatergic mechanism. Clin Exp Immunol. 1987;68(2):384-391.

55. Tan DX, Chen LD, Poeggeler B, et al. Melatonin: a potent endogenous hydroxyl radical scavenger. Endocr J. 1993;1:57-60.

56. Steinhilber D, Brungs M, Werz O, et al. The nuclear receptor for melatonin repress 5-lipoxygenase gene expression in human B lymphocytes. J Biol Chem. 1995;270(13):7037-7040.

57. Reiter RJ. Oxidative processes and antioxidative defense mechanisms in the aging brain. FASEB J. 1995;9(7):526-533.

58. Reiter RJ. Oxidative damage in the central nervous system: protection by melatonin. Prog Neurobiol. 1998;56(3):359-384.

59. Reiter RJ, Maestroni G. Melatonin in relation to the antioxidative defense and immune systems: possible implications for cell and organ transplantation. J Mol Med. 1999;77(1):36-39.

60. Karbownik M, Reiter RJ. Antioxidative effects of melatonin in protection against cellular damage caused by ionizing radiation. Proc Soc Exp Biol Med. 2000;225(1):9-22.

61. Reiter RJ, Tan DX. Melatonin: a novel protective agent against oxidative injury of the ischemic/reperfused heart. Cardiovasc Res. 2003;58(1):10-19.

62. Allegra M, Reiter RJ, Tan DX, Gentile C, Tesoriere L, Livrea MA. The chemistry of melatonin's interaction with reactive species. $J$ Pineal Res. 2003;34(1):1-10.

63. Tan DX, Manchester LC, Sanchez-Barcelo E, Mediavilla MD, Reiter RJ. Significance of high levels of endogenous melatonin in Mammalian cerebrospinal fluid and in the central nervous system. Curr Neuropharmacol. 2010;8(3):162-167.

64. Tan DX, Manchester LC, Liu X, Rosales-Corral SA, Acuna-Castroviejo D, Reiter RJ. Mitochondria and chloroplasts as the original sites of melatonin synthesis: a hypothesis related to melatonin's primary function and evolution in eukaryotes. J Pineal Res. 2013;54(2): 127-138.

65. Qiu T, Yin Y, Li B. PDLLA/PRGD/beta-TCP conduits build the neurotrophin-rich microenvironment suppressing the oxidative stress and promoting the sciatic nerve regeneration. J Biomed Mater Res A. 2014;102(10):3734-3743.

66. Menovsky T, Beek JF. Laser, fibrin glue, or suture repair of peripheral nerves: a comparative functional, histological, and morphometric study in the rat sciatic nerve. J Neurosurg. 2001;95(4):694-699.

67. Pichichero M, Beer B, Clody DE. Effects of dibutyryl cyclic AMP on restoration of function of damaged sciatic nerve in rats. Science. 1973;182(4113):724-725.

68. Cockett SA, Kiernan JA. Acceleration of peripheral nervous regeneration in the rat by exogenous triiodothyronine. Exp Neurol. 1973;39(3):389-394.

69. Roisen FJ, Murphy RA, Pichichero ME, Braden WG. Cyclic adenosine monophosphate stimulation of axonal elongation. Science. 1972;175(4017):73-74.

70. Behram Kandemir Y, Sarikcioglu L. Melatonin and its therapeutic actions on peripheral nerve regeneration. Folia Morphol (Warsz). 2015;74(3):283-289.

71. Kaya Y, Savas K, Sarikcioglu L, Yaras N, Angelov DN. Melatonin leads to axonal regeneration, reduction in oxidative stress, and improved functional recovery following sciatic nerve injury. Curr Neurovasc Res. 2015;12(1):53-62. 
72. Keskin I, Kaplan S, Kalkan S, Sutcu M, Ulkay MB, Esener OB. Evaluation of neuroprotection by melatonin against adverse effects of prenatal exposure to a nonsteroidal anti-inflammatory drug during peripheral nerve development. Int J Dev Neurosci. 2015;41:1-7.

73. Yanilmaz M, Akduman D, Sagun OF, et al. The effects of aminoguanidine, methylprednisolone, and melatonin on nerve recovery in peripheral facial nerve neurorrhaphy. J Craniofac Surg. 2015;26(3):667-672.

74. Matsuyama T, Mackay M, Midha R. Peripheral nerve repair and grafting techniques: a review. Neurol Med Chir (Tokyo). 2000;40(4):187-199.

75. Mekaj AY, Morina AA, Bytyqi CI, Mekaj YH, Duci SB. Application of topical pharmacological agents at the site of peripheral nerve injury and methods used for evaluating the success of the regenerative process. J Orthop Surg Res. 2014;9:94.

76. Onger ME, Kaplan S, Deniz OG, et al. Possible promoting effects of melatonin, leptin and alcar on regeneration of the sciatic nerve. JChem Neuroanat. 2017;81:34-41.

77. Onger ME, Kaplan S, Geuna S. Possible effects of some agents on the injured nerve in obese rats: a stereological and electron microscopic study. J Craniomaxillofac Surg. 2017;45(8):1258-1267.

78. Altun A, Ugur-Altun B. Melatonin: therapeutic and clinical utilization. Int J Clin Pract. 2007;61(5):835-845.

79. Reiter RJ, Tan DX, Leon J, Kilic U, Kilic E. When melatonin gets on your nerves: its beneficial actions in experimental models of stroke. Exp Biol Med (Maywood). 2005;230(2):104-117.

80. Sahna E, Acet A, Ozer MK, Olmez E. Myocardial ischemiareperfusion in rats: reduction of infarct size by either supplemental physiological or pharmacological doses of melatonin. J Pineal Res. 2002;33(4):234-238.

81. Turgut M, Uysal A, Pehlivan M, Oktem G, Yurtseven ME. Assessment of effects of pinealectomy and exogenous melatonin administration on rat sciatic nerve suture repair: an electrophysiological, electron microscopic, and immunohistochemical study. Acta Neurochir (Wien). 2005;147(1):67-77.

82. Davison SP, McCaffrey TV, Porter MN, Manders E. Improved nerve regeneration with neutralization of transforming growth factor-beta 1 . Laryngoscope. 1999;109(4):631-635.

83. Kaplan S, Piskin A, Ayyildiz M, et al. The effect of melatonin and platelet gel on sciatic nerve repair: an electrophysiological and stereological study. Microsurgery. 2011;31(4):306-313.

84. Drobnik J, Dabrowski R. Melatonin suppresses the pinealectomyinduced elevation of collagen content in a wound. Cytobios. 1996;85(340):51-58.

85. Shokouhi G, Tubbs RS, Shoja MM, et al. Neuroprotective effects of high-dose vs low-dose melatonin after blunt sciatic nerve injury. Childs Nerv Syst. 2008;24(1):111-117.

86. Stavisky RC, Britt JM, Zuzek A, Truong E, Bittner GD. Melatonin enhances the in vitro and in vivo repair of severed rat sciatic axons. Neurosci Lett. 2005;376(2):98-101.

87. Khalil Z, Khodr B. A role for free radicals and nitric oxide in delayed recovery in aged rats with chronic constriction nerve injury. Free Radic Biol Med. 2001;31(4):430-439.

88. Naik AK, Tandan SK, Dudhgaonkar SP, et al. Role of oxidative stress in pathophysiology of peripheral neuropathy and modulation by N-acetyl-L-cysteine in rats. Eur J Pain. 2006;10(7):573-579.

89. Kong X, Li X, Cai Z, et al. Melatonin regulates the viability and differentiation of rat midbrain neural stem cells. Cell Mol Neurobiol. 2008;28(4):569-579.

90. Odaci E, Kaplan S. Chapter 16: melatonin and nerve regeneration. Int Rev Neurobiol. 2009;87:317-335.

91. Huerto-Delgadillo L, Anton-Tay F, Benitez-King G. Effects of melatonin on microtubule assembly depend on hormone concentration: role of melatonin as a calmodulin antagonist. J Pineal Res. 1994;17(2):55-62.

92. Atik B, Erkutlu I, Tercan M, Buyukhatipoglu H, Bekerecioglu M, Pence $\mathrm{S}$. The effects of exogenous melatonin on peripheral nerve regeneration and collagen formation in rats. J Surg Res. 2011;166(2):330-336.
93. Turgut M, Kaplan S. Effects of melatonin on peripheral nerve regeneration. Recent Pat Endocr Metab Immune Drug Discov. 2011;5(2):100-108.

94. Chang HM, Huang YL, Lan CT, Wu UI, Hu ME, Youn SC. Melatonin preserves superoxide dismutase activity in hypoglossal motoneurons of adult rats following peripheral nerve injury. J Pineal Res. 2008;44(2):172-180.

95. El-Abhar HS, Shaalan M, Barakat M, El-Denshary ES. Effect of melatonin and nifedipine on some antioxidant enzymes and different energy fuels in the blood and brain of global ischemic rats. J Pineal Res. 2002;33(2):87-94.

96. Sayan H, Ozacmak VH, Ozen OA, et al. Beneficial effects of melatonin on reperfusion injury in rat sciatic nerve. J Pineal Res. 2004;37(3):143-148

97. Okatani Y, Wakatsuki A, Kaneda C. Melatonin increases activities of glutathione peroxidase and superoxide dismutase in fetal rat brain. J Pineal Res. 2000;28(2):89-96.

98. Reiter RJ, Acuna-Castroviejo D, Tan DX, Burkhardt S. Free radicalmediated molecular damage. Mechanisms for the protective actions of melatonin in the central nervous system. Ann N Y Acad Sci. 2001;939:200-215.

99. Reiter RJ, Tan DX, Galano A. Melatonin: exceeding expectations. Physiology (Bethesda). 2014;29(5):325-333.

100. Chang HM, Ling EA, Lue JH, Wen CY, Shieh JY. Melatonin attenuates neuronal NADPH-d/NOS expression in the hypoglossal nucleus of adult rats following peripheral nerve injury. Brain Res. 2000;873(2):243-251.

101. Reiter R, Tang L, Garcia JJ, Munoz-Hoyos A. Pharmacological actions of melatonin in oxygen radical pathophysiology. Life Sci. 1997;60(25):2255-2271.

102. Galindo Moreno P, Avila Ortiz G, Wang HL, Padial Molina M, Ortega Oller I, O'Valle F. The role of melatonin in periodontal and periimplant bone homeostasis and regeneration. J Oral Sci Rehabil. 2016;2(2): $8-15$

103. Mauriz JL, Collado PS, Veneroso C, Reiter RJ, Gonzalez-Gallego J. A review of the molecular aspects of melatonin's anti-inflammatory actions: recent insights and new perspectives. J Pineal Res. 2013;54(1):1-14.

104. Manchester LC, Coto-Montes A, Boga JA, et al. Melatonin: an ancient molecule that makes oxygen metabolically tolerable. J Pineal Res. 2015;59(4):403-419.

105. Reiter RJ, Mayo JC, Tan DX, Sainz RM, Alatorre-Jimenez M, Qin L. Melatonin as an antioxidant: under promises but over delivers. J Pineal Res. 2016;61(3):253-278.

106. Bekyarova G, Tzaneva M. Melatonin ameliorates burn-induced liver injury by modulation of Nrf2 and Nf-kB signalling pathways. SOJ Immunol. 2015;3(2):1-8.

107. Ianăş $\mathrm{O}, \mathrm{Olinescu} \mathrm{R,} \mathrm{Bădescu} \mathrm{I.} \mathrm{Melatonin} \mathrm{involvement} \mathrm{in} \mathrm{oxidative}$ processes. Endocrinologie. 1991;29(3-4):147-153.

108. Reiter RJ. Interactions of the pineal hormone melatonin with oxygen-centered freeradicals: a brief review. Braz J Med Biol Res. 1993;26(11):1141-1155.

109. Lundborg G. A 25-year perspective of peripheral nerve surgery: evolving neuroscientific concepts and clinical significance. J Hand Surg Am. 2000;25(3):391-414.

110. Terenghi G. Peripheral nerve regeneration and neurotrophic factors. J Anat. 1999;194(pt 1):1-14.

111. Webber CA, Christie KJ, Cheng C, et al. Schwann cells direct peripheral nerve regeneration through the Netrin-1 receptors, DCC and Unc5H2. Glia. 2011;59(10):1503-1517.

112. Carey DJ, Bunge RP. Factors influencing the release of proteins by cultured Schwann cells. J Cell Biol. 1981;91(3 pt 1):666-672.

113. Fansa H, Dodic T, Wolf G, Schneider W, Keilhoff G. Tissue engineering of peripheral nerves: epineurial grafts with application of cultured Schwann cells. Microsurgery. 2003;23(1):72-77. 
114. Turgut M, Oktem G, Uysal A, Yurtseven ME. Immunohistochemical profile of transforming growth factor-betal and basic fibroblast growth factor in sciatic nerve anastomosis following pinealectomy and exogenous melatonin administration in rats. $J$ Clin Neurosci. 2006;13(7):753-758.

115. Chang HM, Liu CH, Hsu WM, et al. Proliferative effects of melatonin on Schwann cells: implication for nerve regeneration following peripheral nerve injury. J Pineal Res. 2014;56(3):322-332.

116. Ogata T, Yamamoto S, Nakamura K, Tanaka S. Signalling axis in schwann cell proliferation and differentiation. Mol Neurobiol. 2006;33(1):51-62.

117. Noon LA, Lloyd AC. Treating leprosy: an Erb-al remedy? Trends Pharmacol Sci. 2007;28(3):103-105.

118. Harrisingh MC, Perez-Nadales E, Parkinson DB, Malcolm DS, Mudge AW, Lloyd AC. The Ras/Raf/ERK signalling pathway drives Schwann cell dedifferentiation. EMBO J. 2004;23(15):3061-3071.

119. Syed N, Reddy K, Yang DP, et al. Soluble neuregulin-1 has bifunctional, concentration-dependent effects on Schwann cell myelination. J Neurosci. 2010;30(17):6122-6131.

120. Seo TB, Oh MJ, You BG, et al. ERK1/2-mediated Schwann cell proliferation in the regenerating sciatic nerve by treadmill training. J Neurotrauma. 2009;26(10):1733-1744.

121. Corfas G, Velardez MO, Ko CP, Ratner N, Peles E. Mechanisms and roles of axon-Schwann cell interactions. J Neurosci. 2004;24(42):9250-9260.

122. Hall ED, Braughler JM. Effects of intravenous methylprednisolone on spinal cord lipid peroxidation and $(\mathrm{Na}++\mathrm{K}+)$-ATPase activity. Dose-response analysis during 1st hour after contusion injury in the cat. J Neurosurg. 1982;57(2):247-253.

123. Genovese T, Mazzon E, Muia C, Bramanti P, De Sarro A, Cuzzocrea $\mathrm{S}$. Attenuation in the evolution of experimental spinal cord trauma by treatment with melatonin. J Pineal Res. 2005;38(3):198-208.

124. Kaya Y, Sarikcioglu L, Aslan M, et al. Comparison of the beneficial effect of melatonin on recovery after cut and crush sciatic nerve injury: a combined study using functional, electrophysiological, biochemical, and electron microscopic analyses. Childs Nerv Syst. 2013;29(3):389-401.

125. Kaya Y, Sarikcioglu L, Yildirim FB, Aslan M, Demir N. Does circadian rhythm disruption induced by light-at-night has beneficial effect of melatonin on sciatic nerve injury? J Chem Neuroanat. 2013;53:18-24.

126. Iguchi H, Kato KI, Ibayashi H. Melatonin serum levels and metabolic clearance rate in patients with liver cirrhosis. J Clin Endocrinol Metab. 1982;54(5):1025-1027.

127. Sack RL, Lewy AJ, Hughes RJ. Use of melatonin for sleep and circadian rhythm disorders. Ann Med. 1998;30(1):115-121.

128. Rogerio F, de Souza Queiroz L, Teixeira SA, Oliveira AL, de Nucci G, Langone F. Neuroprotective action of melatonin on neonatal rat motoneurons after sciatic nerve transection. Brain Res. 2002;926(1-2):33-41.
129. Cunnane SC, Manku MS, Horrobin DF. The pineal and regulation of fibrosis: pinealectomy as a model of primary biliary cirrhosis: roles of melatonin and prostaglandins in fibrosis and regulation of $\mathrm{T}$ lymphocytes. Med Hypotheses. 1979;5(4):403-414.

130. Esposito E, Cuzzocrea S. Antiinflammatory activity of melatonin in central nervous system. Curr Neuropharmacol. 2010;8(3):228-242.

131. Turgut M, Uyanikgil Y, Baka M, et al. Pinealectomy exaggerates and melatonin treatment suppresses neuroma formation of transected sciatic nerve in rats: gross morphological, histological and stereological analysis. J Pineal Res. 2005;38(4):284-291.

132. Gul S, Celik SE, Kalayci M, Tasyurekli M, Cokar N, Bilge T. Dosedependent neuroprotective effects of melatonin on experimental spinal cord injury in rats. Surg Neurol. 2005;64(4):355-361.

133. Ulugol A, Dokmeci D, Guray G, Sapolyo N, Ozyigit F, Tamer M. Antihyperalgesic, but not antiallodynic, effect of melatonin in nerveinjured neuropathic mice: possible involvements of the L-arginine-NO pathway and opioid system. Life Sci. 2006;78(14):1592-1597.

134. Golombek DA, Escolar E, Burin LJ, De Brito Sanchez MG, Cardinali DP. Time-dependent melatonin analgesia in mice: inhibition by opiate or benzodiazepine antagonism. Eur J Pharmacol. 1991;194(1): 25-30.

135. Mantovani M, Pertile R, Calixto JB, Santos AR, Rodrigues AL. Melatonin exerts an antidepressant-like effect in the tail suspension test in mice: evidence for involvement of N-methyl-D-aspartate receptors and the L-arginine-nitric oxide pathway. Neurosci Lett. 2003;343(1): $1-4$.

136. Turgut M, Kaplan S, Unal BZ, et al. Stereological analysis of sciatic nerve in chickens following neonatal pinealectomy: an experimental study. J Brachial Plex Peripher Nerve Inj. 2010;5:10.

137. Daglioglu E, Serdar Dike M, Kilinc K, et al. Neuroprotective effect of melatonin on experimental peripheral nerve injury: an electron microscopic and biochemical study. Cent Eur Neurosurg. 2009;70(3):109-114.

138. Zencirci SG, Bilgin MD, Yaraneri H. Electrophysiological and theoretical analysis of melatonin in peripheral nerve crush injury. $J$ Neurosci Methods. 2010;191(2):277-282.

139. Salehi M, Naseri-Nosar M, Ebrahimi-Barough S, et al. Polyurethane/ gelatin nanofibrils neural guidance conduit containing platelet-rich plasma and melatonin for transplantation of Schwann cells. Cell Mol Neurobiol. 2017:1-11.

140. Reiter RJ, Tan DX, Osuna C, Gitto E. Actions of melatonin in the reduction of oxidative stress. J Biomed Sci. 2000;7(6):444-458.

141. Lehman NL, Johnson LN. Toxic optic neuropathy after concomitant use of melatonin, zoloft, and a high-protein diet. J Neuroophthalmol. 1999;19(4):232-234.

142. Piezzi RS, Cavicchia JC. Effects of cold and melatonin on the microtubules of the toad sciatic nerve. Anat Rec. 1981;200(1):115-120.
Journal of Neurorestoratology

\section{Publish your work in this journal}

The Journal of Neurorestoratology is an international, peer-reviewed, open access online journal publishing original research and review articles on the subject of Neurorestoratology. To provide complete coverage of this revolutionary field the Journal of Neurorestoratology will report on relevant experimental research, technological advances,

\section{Dovepress}

and clinical achievements. The manuscript management system is completely online and includes a very quick and fair peer-review system, which is all easy to use. Visit http://www.dovepress.com/testimonials. php to read real quotes from published authors. 